\title{
PENYELESAIAN VEHICLE ROUTING PROBLEM UNTUK EFISIENSI RUTE PENDISTRIBUSIAN PRODUK MINUMAN TEH PUCUK HARUM MENGGUNAKAN METODE SAVING MATRIKS STUDI KASUS (PT.CIPTA NIAGA SEMESTA PALU)
}

\author{
R. Putrafi ${ }^{1}$ dan A. Sahari² \\ 1,2Program Studi Matematika Jurusan Matematika FMIPA Universitas Tadulako \\ Jalan Soekarno-Hatta Km.09 Tondo, Palu 94118, Indonesia \\ 1ramaputrafikarim@gmail.com, 2agus_sh@yahoo.com
}

\begin{abstract}
Vehicle Routing Problem Is a Problem related to the route of product distribution to the consumers. With the existence of these problems a company is expected to seek away a way so that the distribution process can arrive on time to scattered consumers and obtain more efficient routes and costs. Therefore a method which can help the process of scheduling a good route and obtaining optimum costs and efficient delivery was used. One of the methods used was Saving Matrix, which in its operation could efficient the delivery route so that the minimum total distance was obtained. The company's actual mileage was greater than the distance travelled by the route after using the Saving Matrix method. The total difference in distance produced was $106,35 \mathrm{~km}$ or more saving $41,2 \%$ from the actual distance of the company and using Saving Matrix could save the distribution costs of Rp. 5.687 .640 or save $33,8 \%$ of the cost before applying the method.
\end{abstract}

Keywords : : Distribution, Saving Matrix, Vehicle Routing Problem (VRP)

\section{ABSTRAK}

Vehicle Routing Problem Merupakan Permasalahan terkait dengan rute Pendistribusian produk ke tangan konsumen. Dengan adanya permasalahan tersebut suatu perusahaan diharapkan mengupayakan suatu cara agar dalam proses pendistribusian dapat sampai tepat waktu kepada konsumen yang tersebar serta memperoleh rute dan biaya yang lebih efisien. Oleh karena itu digunakan suatu metode yang dapat membantu proses penentuan rute dan memperoleh biaya yang efisien. Salah satu metode yang digunakan adalah Saving Matriks yang dalam pengerjaanya dapat mengefisienkan rute pengiriman sehingga diperoleh total jarak yang minimum. Jarak tempuh aktual perusahaan lebih besar dibandingkan jarak tempuh rute sesudah menggunakan metode Saving Matriks. Selisih total jarak yang dihasilkan yaitu 106,35 km atau lebih hemat 43,21 \% dari jarak aktual perusahaan dan menghemat biaya pendistribusian sebesar Rp. 5.687 .640 atau sebesar 33,8 \% dari biaya sebelum penerapan metode.

Kata kunci : Distribusi, Saving Matriks, Vehicle Routing Problem (VRP) 


\section{PENDAHULUAN}

\subsection{Latar Belakang}

Seiring dengan berkembangnya dunia industri, persaingan antara perusahaan sudah menjadi hal yang lumrah.Setiap perusahaan berlomba - lomba dalam meningkatkan kinerja perusahaan agar kiranya mampu bertahan dalam persaingan global yang semakin maju. Peningkatan kualitas pelayanan terhadap permintaan konsumen menjadi salah satu cara yang dilakukan perusahaan untuk bertahan dalam persaingan industri. Salah satu cara untuk mewujudkan hal tersebut yaitu dengan mengoptimalkan proses ditribusi yang didukung dengan kemajuan teknologi saat ini. Tentunya setiap perusahaan menginginkan penyaluran distribusi yang efektif dengan biaya perjalanan yang minimum.

PT. Cipta Niaga Semesta adalah salah satu perusahaan bagian dari Mayora Group yang bergerak di bidang distribusi produk makanan dan minuman ringan. Sebuah perusahaan yang bergerak di bidang pendistribusian mengusahakan agar produk dapat dengan mudah sampai pada konsumen, dengan cara melakukan proses distribusi tepat waktu terhadapkonsumen yang tersebar. Akan tetapi proses ditribusi yang dilakukan PT. Cipta Niaga Semesta saat ini masih belum efektif dan acak karena tidak memperhatikan lokasi dan jarak konsumen yang dituju, terkadangkendaraan pengangkut mengirim barag ke konsumen yang jaraknya jauhterlebih dahulu. Pemanfaatan alat angkut yang belum maksimal, pengiriman produk ke konsumen dilakukan tanpa memperhatikan rute dan jadwal pengiriman serta dilakukan secara berulang menyebabkan biaya pengiriman menjadi besar karena tidak mempertimbangkan aspek dalam pendistribusian produk. Oleh karena itu perlu dilakukan penentuan rute agar mendapatkan jalur paling optimal yang nantinya akan menghasilkan jarak serta mempengaruhi biaya distribusi barang menjadi lebih optimal.

Permasalahan kegiatan pendistribusian memerlukan suatu strategi agar biaya yang dikeluarkan oleh perusahaan minimal, namun telah memenuhi tujuan utama perusahaaan. Salah satu permasalahan yang termasuk dalam VRP dapat diselesaikan menggunakan metode Saving Matriks. Dengan menggunakan metode Saving Matriks diharapkan dapat mengoptimalkan rute pendistribusian yang nantinya akan meminimalkan jarak yang akan ditempuh kendaraan serta mempengaruhi biaya distribusi yang di keluarkan oleh perusahaan. Menurut Bambang Eko 2008, penentuan biaya yang minimal sangat erat kaitannya dengan jarak yang minimal.

Berdasarkan latar belakang masalah tersebut penulis ingin menuangkan masalah ini kedalam tugas akhir yang berjudul "Penyelesaian Vehicle Routing Problem Untuk Efisiensi Rute Pendistribusian Produk Minuman Teh Pucuk Harum Menggunakan Metode Saving Matriks Studi Kasus PT. Cipta Niaga Semesta Palu ". 


\subsection{Rumusan Masalah}

Berdasarkan latar belakang di atas maka dapat diambil rumusan masalahnya sebagai berikut :

1. Bagaimana menentukan rute yang lebih efisien dalam pendistribusian produk minuman Teh Pucuk Harum dengan menggunakan metode Saving Matriks?

2. Berapa biaya distribusi yang di keluarkan oleh perusahaan setelah penentuan rute menggunakan metode Saving Matriks?

\subsection{Batasan Masalah}

1. Wilayah distribusi meliputi wilayah kota palu.

2. Penelitian ini membahas mengenai rute dan biaya distribusi

3. Konsumen yang dituju diperoleh dari pengambilan data di PT. Cipta Niaga Semesta Palu

4. Konsumen yang dimaksud merupakan pelanggan tetap dan telah memiliki kontrak dengan PT. Cipta Niaga Semesta Palu dengan kurun waktu periode Oktober 2018 Maret 2019

5. Biaya distribusi meliputi biaya tenaga kerja dan biaya bahan bakar (bensin/solar) serta biaya retribusi lain - lain

\section{METODE PENELITIAN}

1. Mulai Penelitian

2. Mengkaji literatur

3. Mengambil data berupa data jarak gudang ke konsumen dan jarak konsumen ke konsumen lainnya, data biaya distribusi berupa biaya transportasi dan retribusi lainnya, kemudian data permintaan konsumen atau Ordersize

4. Mengolah data menggunakan metode Saving Matriks

5. Perhitungan biaya distribusi sebelum dan sesudah penggunaan metode Saving Matriks

6. Hasil

7. Kesimpulan

8. Selesai 


\section{HASIL DAN PEMBAHASAN}

\subsection{Data Nama dan Alamat Konsumen}

Berikut nama dan alamat konsumen yang di sajikan dalam Tabel1 yakni :

Tabel 1 :Data nama dan alamat konsumen

\begin{tabular}{|c|c|c|c|}
\hline NO & Konsumen & Alamat & Kode \\
\hline 1 & Bns Mamboro & Jl. Trans Sulawesi & C1 \\
\hline 2 & Mouza & Jl. Trans Sulawesi & $\mathrm{C} 2$ \\
\hline 3 & Mentari Swalayan & Jl. I Gusti Ngurah Rai & C3 \\
\hline 4 & Royal Supermarket & JI. Danau Lindu & $\mathrm{C} 4$ \\
\hline 5 & Sumber Rejeki & Jl. Tolambu & C5 \\
\hline 6 & Sal Supermarket & Jl. Kelor & C6 \\
\hline 7 & Bns Vetran & Jl. Vetran & $\mathrm{C} 7$ \\
\hline 8 & Bns Diponegoro & Jl. Diponegoro & C8 \\
\hline 9 & Bns Anutapura & Jl. Kangkung & C9 \\
\hline 10 & Mawar Swalayan & JI. Palola & C10 \\
\hline 11 & Bns Dewi Sartika & Jl. Dewi Sartika & C11 \\
\hline 12 & Swalayan Akbar & Jl. Munif Rahman & C12 \\
\hline 13 & Seven Mart & Jl. I Gusti Ngurah Rai & C13 \\
\hline 14 & Anggrek Swalayan & Jl. Touwa & C14 \\
\hline 15 & Bns Touwa & Jl. Touwa & C15 \\
\hline 16 & Gatasa Swalayan & Jl. Dr.Abd Rahman Saleh & C16 \\
\hline 17 & Fitrah Swalayan & Jl. Dewi Sartika & C17 \\
\hline 18 & Nil Swalayan & Jl. Pue Bongo & C18 \\
\hline 19 & Amar Swalayan & Jl. Pue Bongo II & C19 \\
\hline 20 & Ganesha Swalayan & Jl. Pue Bongo & $\mathrm{C} 20$ \\
\hline 21 & Delta Baru Swalayan & JI. Imam Bonjol & $\mathrm{C} 21$ \\
\hline
\end{tabular}

Sumber : PT Cipta Niaga Semesta Oktober 2018 - Maret 2019

\subsection{Rute Awal Pendistribusian}

Rute awal merupakan rute aktual yang digunakan perusahaan untuk mendistribusikan barangnya yang dapat di lihat pada Tabel 2 yakni :

Tabel 2 : Rute Awal Pendistribusian

\begin{tabular}{|l|l|l|}
\hline NO & RUTE & KODE \\
\hline 1 & Rute 1 & DC - C1 - DC \\
\hline 2 & Rute 2 & DC - C2 - C3 - DC \\
\hline 3 & Rute 3 & DC - C4 - C5 - C6 - DC \\
\hline 4 & Rute 4 & DC - C7 - C8 - C9 - DC \\
\hline 5 & Rute 5 & DC - C10 - C11 - C12 - DC \\
\hline 6 & Rute 6 & DC - C13 - C14 - C15 - DC \\
\hline
\end{tabular}




\begin{tabular}{|l|l|l|}
\hline 7 & Rute 7 & DC - C16-C17 - C18 - DC \\
\hline 8 & Rute 8 & DC - C19-C20 - C21 - DC \\
\hline
\end{tabular}

\subsection{Data Jarak Dari Depot Ke Tiap Konsumen}

Data jarak dari gudang menuju Konsumen diperoleh dengan cara pengukuran secara langsung yang disajikan dalam Tabel 3 berikut :

Tabel3 : Jarak dari gudang ke tiap Konsumen

\begin{tabular}{|c|c|c|}
\hline NO & Kode & Jarak (km) \\
\hline 1 & $D C-C 1$ & 2,9 \\
\hline 2 & $\mathrm{DC}-\mathrm{C} 2$ & 4,8 \\
\hline 3 & $\mathrm{DC}-\mathrm{C} 3$ & 15,1 \\
\hline 4 & $\mathrm{DC}-\mathrm{C} 4$ & 11 \\
\hline 5 & $D C-C 5$ & 12,2 \\
\hline 6 & $D C-C 6$ & 12,4 \\
\hline 7 & $D C-C 7$ & 11,6 \\
\hline 8 & $D C-C 8$ & 11,4 \\
\hline 9 & $D C-C 9$ & 13 \\
\hline 10 & $D C-C 10$ & 15 \\
\hline 11 & $D C-C 11$ & 12,3 \\
\hline 12 & $D C-C 12$ & 14 \\
\hline 13 & $D C-C 13$ & 14,5 \\
\hline 14 & $D C-C 14$ & 13,2 \\
\hline 15 & $D C-C 15$ & 14,4 \\
\hline 16 & $D C-C 16$ & 13,3 \\
\hline 17 & DC- C17 & 13,4 \\
\hline 18 & $D C-C 18$ & 13,1 \\
\hline 19 & DC- C19 & 15,2 \\
\hline 20 & $\mathrm{DC}-\mathrm{C} 20$ & 15,4 \\
\hline 21 & $\mathrm{DC}-\mathrm{C} 21$ & 11,2 \\
\hline
\end{tabular}

\subsection{Data Permintaan (Ordersize)}

Data permintaan (Order Size) diperoleh dari perusahaan pada periode bulan Oktober 2018 - Maret 2019 yang telah diambil rata - ratanya pada setiap hari kerja perusahaan.

Tabel 4 : Data Permintaan (Ordersize)

\begin{tabular}{|c|l|c|}
\hline NO & \multicolumn{1}{|c|}{ Konsumen } & $\begin{array}{c}\text { Ordersize } \\
\text { (Dus) }\end{array}$ \\
\hline 1 & Bns Mamboro & 52 \\
\hline 2 & Mouza & 42 \\
\hline 3 & Mentari Swalayan & 35 \\
\hline 4 & Royal Supermarket & 37 \\
\hline 5 & Sumber Rejeki & 39 \\
\hline
\end{tabular}




\begin{tabular}{|c|l|l|}
\hline 6 & Sal Supermarket & 44 \\
\hline 7 & Bns Vetran & 37 \\
\hline 8 & Bns Diponegoro & 36 \\
\hline 9 & Bns Anutapura & 36 \\
\hline 10 & Mawar Swalayan & 39 \\
\hline 11 & Bns Dewi Sartika & 41 \\
\hline 12 & Swalayan Akbar & 36 \\
\hline 13 & Seven Mart & 40 \\
\hline 14 & Anggrek Swalayan & 34 \\
\hline 15 & Bns Touwa & 36 \\
\hline 16 & Gatasa Swalayan & 35 \\
\hline 17 & Fitrah Swalayan & 39 \\
\hline 18 & Nil Swalayan & 36 \\
\hline 19 & Amar Swalayan & 41 \\
\hline 20 & Ganesha Swalayan & 36 \\
\hline 21 & Delta Baru Swalayan & 44 \\
\hline & & \\
\hline
\end{tabular}

\subsection{Data Biaya}

Data biaya yang berkaitan dengan pendistribusian minuman teh pucuk harum dari distributor sampai ke tangan konsumen di sajikan dalam Tabel 5berikut :

Tabel 5 : Data Biaya Distribusi

\begin{tabular}{|c|c|l|}
\hline NO & Jenis Biaya & \multicolumn{1}{c|}{ Jumlah (Rp) } \\
\hline 1 & Tenaga Kerja/ Sopir dan Kernet & @Rp.20.000/Perjalanan \\
\hline 2 & Bahan Bakar & Rp.5.500/Liter (solar) \\
\hline 3 & Biaya Admin & Rp.50.000/hari kerja \\
\hline \multirow{2}{*}{4} & Biaya Konsumsi & $\begin{array}{l}\text { @Rp.30.000/hari } \\
\text { 2xRp.30.000/hari } \\
=\text { Rp.60.000/hari }\end{array}$ \\
& & \\
\hline
\end{tabular}

\subsection{Data Alat Angkut}

Jenis alat angkut atau armada yang digunakan dalam pendistribusian distributor ke tangan konsumen disajikan dalam Tabel 6 berikut :

Tabel 6 : Data Alat Angkut

\begin{tabular}{|c|c|c|c|}
\hline Jenis Alat Angkut & Kapasitas & Jumlah & Keterangan \\
\hline $\begin{array}{c}\text { Pick UP Box } \\
\text { (L300) }\end{array}$ & 200 Box/Dus & 1 & Milik Sendiri \\
\hline
\end{tabular}

Mobil Pick UP L300 dapat menempuh jarak $5 \mathrm{~km}$ untuk tiap 1 liter solar ( Sumber : Sopir PT. Cipta Niaga Smesta Palu ) 


\subsection{Perhitungan Jarak Menggunakan Saving Matriks}

Perhitungan saving matriks di hitung berdasarkan matriks jarak awal distributor ke konsumen dan konsumen ke konsumen lainnya. Dengan menggunakan rumus penghematan atau saving matriks

Dalam menghitung penghematan jarak dari distributor ke konsumen dan dari konsumen ke konsumen lainnya digunakan rumus saving matriks yang secara matematis dituliskan sebagai berikut :

$$
S(C 1, C 2)=J(D C, C 1)+J(D C, C 2)-J(C 1, C 2)
$$

Dimana :

$S(C 1, C 2) \quad=$ Penghematan jarak antara konsumen 1 dan konsumen 2

$J(D C, C 1) \quad=$ Jarak dari distributor ke konsumen 1 atau sebaliknya

$J(D C, C 2) \quad=$ Jarak dari distributor ke konsumen 2 atau sebaliknya

$J(C 1, C 2) \quad=$ Jarak dari konsumen 1 ke konsumen 2 atau sebaliknya

Berdasarkan pada tabel matriks jarak pada lampiran dapat di hitung penghematan jarak sebagai berikut :

Contoh perhitungan jarak dari C1 (BNS Mamboro) ke C2 (Mouza) :

$$
\begin{aligned}
& S(C 1, C 2)=J(D C, C 1)+J(D C, C 2)-J(C 1, C 2) \\
& =2,9+4,8-7,7 \\
& =0 \mathrm{Km}
\end{aligned}
$$

\subsection{Pengalokasian Produk Ke Konsumen Untuk Tiap Alat Angkut}

Pengalokasian produk ke tiap alat angkut diselesaikan dengan iterasi yakni dengan melihat jarak penghematan terbesar kemudian mengalokasikannya ke dalam rute dengan melihat kapasitas angkut armada.Apabila pengalokasian produk tidak melebihi kapasitas angkut, maka rute layak digunakan. Apabila produk melebihi batas angkut armada maka pengalokasian produk ke rute tersebut tidak layak digunakan seperti pada iterasi berikut :

1. Memilih nilai terbesar dari matriks penghematan yaitu 30,1 pada konsumen dengan kode $(C 19, C 20)$ yaitu Amar swalayan dan Ganesha Swalayan kemudian mencoret seluruh kolom dan baris dari nilai penghematan terbesar yang terpilih. Selanjutnya menggabungkan C19 dan C20 menjadi satu rute. Rute yang terbentuk adalah : Rute $\mathrm{A}, \mathrm{C} 19$ dan C20 dengan permintaan $41+36=77$. Jumlah permintaan pada rute ini belum melampaui kapasitas kendaraan

2. Memilih nilai terbesar dari matriks penghematan selanjutnya, yaitu 28,2 pada konsumen dengan kode (C13,C19) yaitu Seven Mart dan Amar Swalayan oleh karena C19 telah teralokasi maka dilakukan penambahan $\mathrm{C} 13$ pada rute $\mathrm{A}$ maka rute yang terbentuk adalah : $\mathrm{C} 19$ - C20 - C13 dengan total jumlah permintaan $41+36+40=117$ jumlah permintaan pada rute ini belum melampaui kapasitas kendaraan. 
3. Memilih nilai terbesar selanjutnya pada matriks penghematan yaitu 27,5 pada konsumen dengan kode $(\mathrm{C} 14, \mathrm{C} 15)$ yaitu Anggrek Swalayan dan Bns Touwa selanjutnya mencoret kolom dan barisnya kemudian menggabungkan $(\mathrm{C} 14, \mathrm{C} 15)$ kedalam rute A maka rute yang terbentuk adalah C19 - C20 - C13 C14 - C15 dengan jumlah permintaan $41+36+40+34+36=187$ jumlah permintaan pada rute ini belum melampaui kapasitas kendaraan.

4. Memilih nilai terbesar selanjutnya pada matriks penghematan yaitu 26,3 pada konsumen dengan kode $(\mathrm{C} 9, \mathrm{C} 10)$ kemudian mencoret kolom dan barisnya kemudian menggabungkan $(\mathrm{C} 9, \mathrm{C} 10)$ kedalam rute $\mathrm{A}$ sehingga rute yang terbentuk $\mathrm{C} 19-\mathrm{C} 20-\mathrm{C} 13-\mathrm{C} 14-\mathrm{C} 15-\mathrm{C} 9-\mathrm{C} 15$ dengan jumlah permintaan $41+36+40+34+36+36+39=262$ namun jumlah ini telah melebihi kapasitas armada angkut sehingga diperlukan pembentukan rute baru.

5. Penentuan rute selanjutnya dilakukan sebagaimana langkah awal pembentukan rute dan dimulai dengan nilai penghematan terbesar dengan melihat jarak antar konsumen pada matriks jarak.

6. Prosedur ini dilakukan berulang sehingga semua konsumen telah teralokasi dalam rute.

\subsection{Pengurutan Rute Pengiriman dengan Ketetanggaan Terdekat}

Dari iterasi diatas kemudian diperoleh 5 rute baru yaitu : Rute A (DC - C19 - C20 $C 13-C 14-C 15-D C)$ Rute B (DC - C9 - C10 - C12 - C21 - C8 - DC), rute C (DC $\mathrm{C} 4-\mathrm{C} 5-\mathrm{C} 6-\mathrm{C} 3-\mathrm{C} 18-\mathrm{DC})$, rute $\mathrm{D}(\mathrm{DC}-\mathrm{C} 2-\mathrm{C} 7-\mathrm{C} 16-\mathrm{C} 11-\mathrm{C} 17-\mathrm{DC})$ dan rute $E(D C-C 1-D C)$.

1. Dari hasil iterasi diatas diperoleh rute $\mathrm{A}$ dengan urutan pendistribusian menurut konsumen terdekat adalah dari DC - C14 - C15 - C13 - C20 - C19 - DC dengan panjang rute :

$13,2 \mathrm{~km}+1,3 \mathrm{~km}+3,6 \mathrm{~km}+1,6 \mathrm{~km}+0,4 \mathrm{~km}+15,4 \mathrm{~km}=35,5 \mathrm{~km}$

2. Dari hasil iterasi diatas diperoleh rute $B$ dengan urutan pendistribusian menurt konsumen terdekat adalah dari DC - C21 - C9 - C10 - C8 - C12-DC dengan panjang rute :

$11,2 \mathrm{~km}+1,6 \mathrm{~km}+0,5 \mathrm{~km}+2,5 \mathrm{~km}+3,6 \mathrm{~km}+14,1 \mathrm{~km}=33,5 \mathrm{~km}$

3. Dari hasil iterasi diatas diperoleh rute $\mathrm{C}$ dengan urutan pendistribusian menurt konsumen terdekat adalah dari DC - C4 - C6 - C5 - C18 - C3 - DC dengan panjang rute ;

$11 \mathrm{~km}+0,45 \mathrm{~km}+1,7 \mathrm{~km}+2,4 \mathrm{~km}+3,3 \mathrm{~km}+15,1 \mathrm{~km}=33,95 \mathrm{~km}$

4. Dari hasil iterasi diatas diperoleh rute $\mathrm{D}$ dengan urutan pendistribusian menurt konsumen terdekat adalah dari DC - C2 - C7 - C16-C11-C17- DC dengan panjang rute :

$4,8 \mathrm{~km}+8,1 \mathrm{~km}+2,9 \mathrm{~km}+0,5 \mathrm{~km}+1,3 \mathrm{~km}+13,4=31 \mathrm{~km}$ 
5. Dari hasil iterasi diatas diperoleh rute terakhir adalah DC - C1 - DC dengan panjang rute : $2,9 \mathrm{~km}+2,9 \mathrm{~km}=5,8 \mathrm{~km}$

\subsection{Perhitungan Biaya Bahan Bakar Setelah Penggunaan Saving Matriks}

Dari biaya transportasi awal dapat dihitung biaya transportasi setelah penerapan metode saving matriks diperoleh rute baru dengan biaya sebagai berikut :

1. Rute $A: 35,5 \mathrm{~km} \times 1 / 5 \times \mathrm{Rp} .5 .500$

2. Rute $B: 33,5 \mathrm{~km} \times 1 / 5 \times$ Rp. 5.500

3. Rute $C: 33,95 \mathrm{~km} \times 1 / 5 \times$ Rp. 5.500

4. Rute D : $31 \mathrm{~km} \times 1 / 5 \times$ Rp. 5.500

5. Rute E : $5,8 \mathrm{~km} \times 1 / 5 \times$ Rp. 5.500
$=$ Rp. 39.050

$=$ Rp. 36.850

$=$ Rp. 37.345

$=$ Rp. 34.100

$=$ Rp. 6.380

Total jarak rute baru setelah penerapan saving matriks yaitu :35,5+33,5+33,95+31 $+5,8=139,75 \mathrm{~km}$ Sehingga diperoleh keseluruhan biaya distribusi pada rute usulan sebagai berikut :

Total biaya bahan bakar :

Rp. $39.050+$ Rp. $36.850+$ Rp. $37.345+$ Rp. $34.100+$ Rp. $6.380=$ Rp. 153.725

Total biaya tenaga kerja / Sopir : $2 \times$ Rp. $20.000 \times 5$ Rute $=$ Rp.200.000

Total Biaya Konsumsi Sopir / hari kerja : Rp. $30.000 \times 2=$ Rp.60.000

Total biaya admin : Rp 50.000/ hari kerja

Total biaya bahan bakar awal perhari kerja selama 6 bulan yakni Oktober 2018 - Maret 2019:

Total biaya bahan bakar + total biaya tenaga kerja + total biaya konsumsi + total biaya admin $=$ Rp. $153.725+$ Rp. $200.000+$ Rp. $60.000+$ Rp.50.000 = Rp.463.725 / hari kerja Kemudian selama 6 bulan terdapat 24 hari kerja ( 1 bulan terdapat 4 hari kerja ) maka di peroleh total biaya yang di keluarkan pihak distributor selama periode Oktober 2018 - Maret 2019 :

Rp.463.725 x 24 = Rp. 11.129 .400 .

\subsection{Perbandingan Rute / jalur Distribusi}

Rute, jarak, ordersize sebelum dan sesudah penerapan metode saving matriks serta perbandingannya dapat di lihat pada Table 7, Tabel 8, dan Tabel 9 berikut :

Tabel 7 :Perbandingan Rute / Jalur Distribusi

\begin{tabular}{|c|c|c|c|c|}
\hline NO & RUTE & KODE & $\begin{array}{c}\text { Jarak Total } \\
\text { Perjalanan }( \pm)\end{array}$ & $\begin{array}{l}\text { Order Size } \\
\text { (Dus) }\end{array}$ \\
\hline 1 & Rute 1 & $D C-C 1-D C$ & $5,8 \mathrm{Km}$ & 52 \\
\hline 2 & Rute 2 & $D C-C 2-C 3-D C$ & $33,8 \mathrm{Km}$ & 77 \\
\hline 3 & Rute 3 & $\mathrm{DC}-\mathrm{C} 4-\mathrm{C} 5-\mathrm{C} 6-\mathrm{DC}$ & $26,9 \mathrm{Km}$ & 120 \\
\hline 4 & Rute 4 & $\mathrm{DC}-\mathrm{C} 7-\mathrm{C} 8-\mathrm{C} 9-\mathrm{DC}$ & $35,4 \mathrm{Km}$ & 109 \\
\hline 5 & Rute 5 & $\mathrm{DC}-\mathrm{C} 10-\mathrm{C} 11-\mathrm{C} 12-\mathrm{DC}$ & $46,4 \mathrm{Km}$ & 116 \\
\hline 6 & Rute 6 & $\mathrm{DC}-\mathrm{C} 13-\mathrm{C} 14-\mathrm{C} 15-\mathrm{DC}$ & $31,9 \mathrm{Km}$ & 110 \\
\hline 7 & Rute 7 & $\mathrm{DC}-\mathrm{C} 16-\mathrm{C} 17-\mathrm{C} 18-\mathrm{DC}$ & $33,9 \mathrm{Km}$ & 110 \\
\hline
\end{tabular}




\begin{tabular}{|c|c|c|c|c|}
\hline 8 & Rute 8 & DC - C19 - C20 - C21 - DC & $32 \mathrm{Km}$ & 121 \\
\hline \multicolumn{2}{|c|}{ TOTAL } & $246,1 \mathrm{Km}$ & 815 \\
\hline
\end{tabular}

Tabel 8 : Jarak,Rute dan Ordersize Setelah Penerapan Metode saving matriks

\begin{tabular}{|c|c|c|c|c|}
\hline NO & RUTE & KODE & $\begin{array}{c}\text { Jarak Total } \\
\text { Perjalanan }(\mathrm{km})\end{array}$ & $\begin{array}{c}\text { Order } \\
\text { Size } \\
\text { (Dus) }\end{array}$ \\
\hline 1 & Rute A & $\begin{array}{l}\text { DC-C14-C15-C13-C20-C19- } \\
\text { DC }\end{array}$ & $35,5 \mathrm{Km}$ & 187 \\
\hline 2 & Rute B & $\begin{array}{l}\mathrm{DC}-\mathrm{C} 21-\mathrm{C} 9-\mathrm{C} 10-\mathrm{C} 8- \\
\mathrm{C} 12-\mathrm{DC}\end{array}$ & $33,5 \mathrm{Km}$ & 191 \\
\hline 3 & Rute C & $\begin{array}{l}\mathrm{DC}-\mathrm{C} 4-\mathrm{C} 6-\mathrm{C} 5-\mathrm{C} 18-\mathrm{C} 3- \\
\mathrm{DC}\end{array}$ & $33,95 \mathrm{Km}$ & 191 \\
\hline 4 & Rute D & $\begin{array}{l}\mathrm{DC}-\mathrm{C} 2-\mathrm{C} 7-\mathrm{C} 16-\mathrm{C} 11- \\
\mathrm{C} 17-\mathrm{DC}\end{array}$ & $31 \mathrm{Km}$ & 194 \\
\hline 5 & Rute E & $D C-C 1-D C$ & $5,8 \mathrm{Km}$ & 52 \\
\hline \multicolumn{3}{|r|}{ TOTAL } & $139,75 \mathrm{Km}$ & 815 \\
\hline
\end{tabular}

Tabel 9 : Perbandingan Rute Awal dan Rute Baru

\begin{tabular}{|c|c|c|c|}
\hline $\begin{array}{c}\text { Total jarak pada } \\
\text { rute awal }(\mathrm{Km})\end{array}$ & $\begin{array}{c}\text { Total jarak pada } \\
\text { rute baru }(\mathrm{Km})\end{array}$ & $\begin{array}{c}\text { Selisih Jarak } \\
(\mathrm{Km})\end{array}$ & $\begin{array}{c}\text { Penghematan } \\
(\%)\end{array}$ \\
\hline $246,1 \mathrm{Km}$ & 139,75 & $106,35 \mathrm{Km}$ & $43,21 \%$ \\
\hline
\end{tabular}

\subsection{Perbandingan Distribusi}

Dengan menggunakan metode saving matriks terhadap rute distribusi, maka diperoleh perbandingan biaya distribusi yang disajikan dalam Tabel 10 berikut :

Tabel 10 :Perbandingan Biaya Distribusi awal dan biaya distribusi baru

\begin{tabular}{|c|c|c|c|}
\hline $\begin{array}{c}\text { Total biaya } \\
\text { distribusi pada } \\
\text { rute awal (Rp) }\end{array}$ & $\begin{array}{c}\text { Total biaya } \\
\text { distribusi pada } \\
\text { rute baru (Rp) }\end{array}$ & $\begin{array}{c}\text { Penghematan } \\
(\mathrm{Rp})\end{array}$ & $\begin{array}{c}\text { Penghematan } \\
(\%)\end{array}$ \\
\hline $\begin{array}{c}\text { Rp.700.710/hari } \\
\text { kerjaAtau }\end{array}$ & $\begin{array}{c}\text { Rp.463.725/hari } \\
\text { kerjaAtau }\end{array}$ & $\begin{array}{c}\text { Rp.236.985/hari } \\
\text { kerjaAtau }\end{array}$ & \\
Rp.16.817.040 & Rp.11.129.400/ & Rp.5.687.640 & $33,8 \%$ \\
/Oktober 2018 - & Oktober 2018 - & /Oktober 2018- \\
Maret 2109 & Maret 2019 & Maret 2019 & \\
\hline
\end{tabular}

\subsection{Pembahasan}

Dari Table 10 dapat dilihat bahwa pada rute awal yag digunakan oleh perusahaan adalah sebanyak 8 rute pengiriman dengan total jarak $246,1 \mathrm{Km}$, sedangkan dengan menerapkan metode saving matriks diperoleh rute pengiriman yang lebih efisien sebanyak 5 
rute dengan total jarak 139,75 Km atau dengan selisih 106,35 Km sehingga dapat dikatakan terjadi penghematan jarak sebesar $43,21 \%$ sementara untuk biaya distribusi dari table diatas dapat kita lihat perhitungan biaya distribusi awal yang digunakan oleh perusahaan adalah sebesar Rp.700.710/ hari kerja atau Rp.16.817.040/ Oktober 2018 - Maret 2019 sedangkan biaya distribusi setelah menggunakan rute baru adalah sebesar Rp. 463.725 / hari kerja atau Rp.11.129.400/ Oktober 2018 - Maret 2019 sehingga diperoleh penghematan Rp.236.985/hari kerja atau Rp.5.687.640/ Oktober 2018 - Maret 2019 sehingga perusahaan menghemat dapat menghemat biaya pendistribusian sebanyak $33,8 \%$ dari biaya pendistribusian sebelumnya .

\section{KESIMPULAN}

Pada penelitian ini, maka dapat disimpulkan bahwa : dari 8 rute awal pendistribusian berubah menjadi 5 rute baru, rute yang ditentukan meliputi rute $A$ sampai dengan rute $E$ dengan total jarak tempuh 139,75 Km. Dimana 5 rute baru tersebut diperoleh setelah penerapan metode saving matriks dan didapatkan total jarak dan biaya yang effisien.

Rute baru setelah penerapan metode saving matriks pada pengiriman minuman teh pucuk harum ke konsumen adalah sebagai berikut :

1. Rute $A: D C-C 14-C 15-C 13-C 20-C 19-D C$ dengan panjang rute: $13,2 \mathrm{~km}+1,3 \mathrm{~km}$ $+3,6 \mathrm{~km}+1,6 \mathrm{~km}+0,4 \mathrm{~km}+15,4 \mathrm{~km}=35,5 \mathrm{~km}$

2. Rute $B: D C-C 21-C 9-C 10-C 8-C 12-D C$ dengan panjang rute: $11,2 \mathrm{~km}+1,6 \mathrm{~km}+$ $0,5 \mathrm{~km}+2,5 \mathrm{~km}+3,6 \mathrm{~km}+14,1 \mathrm{~km}=33,5 \mathrm{~km}$

3. Rute $\mathrm{C}: \mathrm{DC}-\mathrm{C} 4-\mathrm{C} 6-\mathrm{C} 5-\mathrm{C} 18-\mathrm{C} 3-\mathrm{DC}$ dengan panjang rute : $11 \mathrm{~km}+0,45 \mathrm{~km}+$ $1,7 \mathrm{~km}+2,4 \mathrm{~km}+3,3 \mathrm{~km}+15,1 \mathrm{~km}=33,95 \mathrm{~km}$

4. Rute $D$ : $D C-C 2-C 7-C 11-C 16-C 17-D C$ dengan panjang rute : $4,8 \mathrm{~km}+8,1 \mathrm{~km}+$ $2,9 \mathrm{~km}+0,5 \mathrm{~km}+1,3 \mathrm{~km}+13,4=31 \mathrm{~km}$

5. Rute $E: D C-C 1-D C$ dengan panjang rute : $2,9 \mathrm{~km}+2,9 \mathrm{~km}=5,8 \mathrm{~km}$

Sehingga melihat jarak tempuh setelah penggunaan metode saving matriks mengalami selisih $106,35 \mathrm{~km}$ atau penghematan rute sebesar $43,21 \%$. Dengan penghematan biaya distribusi setelah mendapatkan rute baru dapat disimpulkan biaya total awal Rp.700.710/ hari kerja atau Rp.16.817.040/ Oktober 2018 - Maret 2019 sedangkan biaya distribusi setelah menggunakan rute baru adalah sebesar Rp. 463.725 / hari kerja atau Rp.11.129.400/ Oktober 2018 - Maret 2019 sehingga diperoleh penghematan Rp.236.985 /hari kerja atau Rp5.687.640 / Oktober 2018 - Maret 2019 sehingga perusahaan dapat menghemat biaya pendistribusian sebanyak $33,8 \%$ dari biaya pendistribusian sebelumnya, dapat dikatakan pula bahwa metode saving matriks ini effisien digunakan dalam kasus penentuan rute pendistribusian. 


\section{DAFTAR PUSTAKA}

[1] Gunawan, P, "Enhanced Nearest Neighbors Algorithm for Design of water Network", Chemical Engineering Science,Halaman 197-206, 2012.

[2] Hendrawan,B.Eko, Implementasi Algoritma Paralel Algorithm Untuk Penyelesaian Heterogeneous Fleet Vehicle Routing problem, Jurusan tekhnik Informatika. Institut Tekhnologi Sepuluh Nopember, Volume 01 halaman 14, Surabaya, 2007.

[3] Istantiningrum, M,Penentuan Rute Pengiriman dan Penjadwalan Dengan Menggunakan Metode Saving Matriks Studi Kasus Pada PT. Sukanda Djaya Yogyakarta, Jurnal Tekhnik Industri UIN Sunan Kalijaga, Volume 02 halaman 12, Yogyakarta, 2010.

[4] Pujawan . I.Y, Supply Chain Management, Guna widya, 2005, Yogyakarta, edisi ke 2 halaman : $180-184$.

[5] Tjiptono, Fandy, ANDI, 2008, Strategi Pemasaran, edisi 3, Yogyakarta. 